\title{
PENSAMIENTO DEL PROFESORADO CHILENO ACERCA DE LA CARRERA DOCENTE: EVIDENCIAS 2011-2019
}

\section{Cristián Venegas Traverso ${ }^{1}$}

\begin{abstract}
RESUMEN
El estudio revisa la evidencia científica producida en el período 2011-2019, respecto del pensamiento del profesorado escolar chileno sobre la Carrera Docente. Se desarrolla una metodología cualitativa, con un diseño tipo revisión sistemática, indagando en reportes, artículos e informes de investigación producidos entre 2011 y 2019, seleccionándose 34 fuentes. Para el análisis se levantaron siete categorías apriorísticas. Las conclusiones manifiestan una opinión contradictoria sobre la Formación Inicial Docente (FID), la repetida necesidad de vincular universidad y escuela, una participación importante en instancias de formación continua, una visión negativa de la Evaluación Docente, un sentimiento de valoración de la comunidad educativa pero no del Estado, y el discurso instalado sobre la sobrecarga de trabajo y el agobio laboral.
\end{abstract}

Conceptos clave: competencias del docente, formación de docentes, perfeccionamiento, política educacional, pensamiento docente.

\section{THOUGHTS OF CHILEAN TEACHERS ABOUT TEACHING CAREER: EVIDENCE 2011-2019}

\begin{abstract}
The study reviews the scientific evidence produced in the period 2011-2019, regarding the thoughts of Chilean school teachers about teaching career. A qualitative methodology is developed with a design type systematic review, looking into reports, articles and research summaries produced between 2011 and 2019, finally selecting 34 sources. For analysis seven aprioristic categories were raised. The conclusions show a contradictory opinion about initial teacher training, a repeated need to link universities and schools, an important participation in cases of continuous training, a negative vision of Teacher Evaluations, a feeling of valuation from the educational community, but not from the State, and the discourse installed regarding work overload and burnout.
\end{abstract}

Key concepts: teacher competencies, teacher training, improvement, educational policy, teacher thinking, teacher discourse.

1 Universidad Mayor, Santiago, Chile. Contacto: cristian.venegas@umayor.cl 


\section{Problematización}

La visión del profesorado en ejercicio sobre las necesidades formativas de la profesión no se ha reflejado mayormente en la política educativa para la Formación Inicial Docente (FID) (Ferrada, Villena y Turra, 2015; Figueroa y Cavieres, 2020). Asimismo, los mecanismos de apoyo para el Desarrollo Profesional Docente (DPD) se han fundado principalmente en la información que reportan las evaluaciones directas de desempeño -Evaluación Docente y "encasillamiento" en el contexto de la ley de Carrera Docente, N²0.903, 2016-y datos indirectos (pruebas SIMCE y de selección universitaria, PSU), mas no necesariamente en el pensamiento docente, aunque se ha pretendido mostrar lo contrario (Cavieres y Apple, 2016).

En efecto, una revisión a las políticas chilenas para la carrera docente (FID y DPD) desde el regreso de la democracia (1990) confirma una mirada administrativa, técnica y externa al contexto escolar y al trabajo docente (Comisión Nacional de Acreditación, 2018), en una tensión permanente entre la rendición de cuentas (control) y la compensación formativa (apoyo) (Ávalos, 2014).

Puesto al límite, no es novedad que el apoyo del Estado al profesorado puede enmascarar cierta condescendencia, asistencialismo y desvaloración profesional, algo posible de estimar según el grado en que el aporte docente es acogido en la política pública y sus efectos concretos. En este sentido, paradójicas son dos políticas docentes controversiales: Evaluación Docente (Ley No 16.961, 2004) y Marco para la Buena Enseñanza (MBE) (2008). Inéditamente para las definiciones de políticas docentes, la construcción del MBE comprometió la opinión del magisterio, a través del Colegio de Profesoras y Profesores (CP)—su representación gremial_- y una votación consultiva sobre su contenido (Roa, 2017). A su vez, la Evaluación Docente implicó un acuerdo entre MINEDUC, la Asociación Chilena de Municipalidades y el CP (Sepúlveda, Hernández-Mosqueira, Peña-Troncoso, Troyano y Opazo, 2019). No obstante, sin devaluar el avance que supusieron, la Evaluación Docente y el MBE han contribuido a la "paradoja histórica de un sistema que plantea desafíos profesionales a sus docentes y en la 
práctica los desprofesionaliza" (Ruffinelli, 2016, p. 263). Muestra de esto es lo descrito en el MBE: "El profesionalismo de los docentes chilenos es parte de una tradición educacional que hay que consolidar y renovar. Es también un sentido que los profesores y profesoras de hoy deben compartir, para proyectar en la sociedad una imagen concordante con dicha tradición" (MINEDUC, 2008, p. 40).

De acuerdo con esto, se extrae que el docente chileno es "profesional", pero necesita "consolidar" tal profesionalismo a través del MBE y demostrarlo socialmente. La divagación sobre la condición "profesional" del docente (iantes o después de operacionalizar la MBE en su práctica?) develaría cierta inmadurez en el diseño de estas políticas y la levedad con que fue conceptualizado el "profesionalismo". Que un profesional precise de un marco que le "ayude" a ser "profesional" puede resultar contradictorio desde un punto de vista hasta temporal. Lo complejo es que, bajo esta indefinición, el profesorado es evaluado y sometido a procesos que repercuten en él, profesional y laboralmente.

Otro caso es el programa INICIA (2008), una política que definió, por un lado, los puntajes mínimos de ingreso a las carreras pedagógicas y, por otro, la aplicación de diagnósticos individuales al inicio de la formación, y una prueba obligatoria en el penúltimo año de carrera (Evaluación Nacional Diagnóstica, EDN), cuyos resultados no interfieren en la titulación. La EDN —-denominación actualtiene hasta hoy como referente a los Estándares Orientadores para Egresados de Carreras de Pedagogía (Ministerio de Educación, 2012), un marco de desempeño construido con una mínima participación de agentes del sistema escolar y sin aportes reconocidos del profesorado en su producción. Este último hecho podría afectar la validez de los propios estándares, al no ser suficientemente representativos de los escenarios reales del ejercicio profesional, aspecto que sí domina el profesorado excluido. Pero sus efectos pueden ser mayores: la ley de Carrera Docente establece que la acreditación de un programa de pedagogía depende, entre otros, de que sus procesos formativos se enmarquen en estos estándares de desempeño (Schilling y Sánchez, 2020). 
Por otro lado, la ley de Carrera Docente se configura como el hito más importante del último tiempo sobre la profesión, al conciliar dos etapas culturalmente separadas en el profesorado: FID y DPD. La nueva norma vino a oficializar a la profesión como una trayectoria que parte con el ingreso a la formación inicial y culmina en el retiro/jubilación, reconociendo la experiencia y los aprendizajes logrados durante la carrera, no sin someterse a los debidos procesos de evaluación oficial (como la acreditación de competencias profesionales). Sin embargo, en cuanto al protagonismo del gremio docente, este solo participó en la gestión de la ley mediante una consulta, siendo sus contribuciones menores en relación con las que sí instalaría en el texto final, por ejemplo, la Organización para la Cooperación y el Desarrollo Económico (OCDE) y la idea de "cultura evaluativa" en la carrera (Cavieres y Apple, 2016).

En suma, la ausencia generalizada del profesorado y su pensamiento en la producción de las políticas docentes en Chile, por ejemplo en la FID (Ferrada, 2017), es confirmada por los casos descritos. Esta contrariedad produce, sin duda, un cisma entre las definiciones-decisiones del Estado y los problemas sociales, escolares y docentes en el sistema educativo que pueden ser expresados por el profesorado, arriesgando el éxito de las primeras y agudizando los segundos.

En este contexto, y para densificar las futuras políticas para la carrera docente en Chile con las necesidades, demandas y conflictos - factuales y territorializados- del profesorado, resulta vital evidenciarlas desde fuentes confiables y rigurosas. Para ello, este trabajo propone identificar el pensamiento del profesorado chileno sobre la carrera docente a partir de la revisión de la producción científica entre 2011 y 2019.

\section{Antecedentes teóricos}

\subsection{Pensamiento docente}

La preocupación académica por el pensamiento docente (PD) ha supuesto un avance en la comprensión acerca del profesorado. Al 
integrar en los análisis las creencias, teorías, motivaciones y saberes de este grupo, se ha podido explicar sus conductas y acciones profesionales, y, además, identificar las necesidades y aspiraciones del contexto de desempeño profesional.

En términos generales, el PD responde al modo, explícito o implícito, en que el docente comprende, representa e interpreta la realidad educativa, para luego expresarlo en decisiones y acciones (Guzmán, 2013). Bajo esta conceptualización amplia de PD han emergido otros constructos: creencias, concepciones y teorías implícitas y explícitas, entre otros.

La base del PD son las creencias docentes, es decir, ideas, construcciones mentales, representaciones, constructos personales o metáforas; de carácter personal-afectivo, experiencial, social, práctico, inconsciente y carente de reflexión crítica; sobre elementos de la profesión y la educación (Oliver, 2009, citado por Cortez, Fuentes, Villablanca y Guzmán, 2013; Rojas, 2014; Donoso, Rico y Castro, 2016; Pontes, Poyato y Oliva, 2018; Beyer, Miranda y Arancibia, 2019). A pesar de su adquisición sencilla y aparente irracionalidad, las creencias son relevantes al servir de guía individual "para definir y comprender, desde la propia persona, al mundo que le rodea" (Gómez-López y Cano, 2011, p. 73).

Las creencias tampoco son asuntos simples: están en un nivel abstracto y complejo, apenas consciente para el sujeto, sus pares y la escuela (Aziz, 2018). Claves en su configuración son, por un lado, la ausencia de barreras críticas en la aprehensión de la creencia por parte del sujeto, facilitando su integración ciega en el pensamiento, $y$, por otro, el peso de la acción/experiencia del sujeto sobre la creencia (Pontes et al., 2018). Lo último opera bajo una lógica de retroalimentación: mientras la acción se realiza con fundamento en la creencia, ésta se profundiza en el sujeto mediante su reproducción en la acción, en un proceso de autoatribución (Gómez-López y Cano, 2011).

Como reportan Pontes et al. (2018), la solidificación de las creencias complica las posibilidades de cambio en el PD del sujeto. 
Esto explicaría por qué la enseñanza y aprendizajes en la FID resulta menos influyente que la experiencia acumulada —niñez incluidaen la construcción de creencias en el docente (Imbernón, 2005; Gómez, 2010, citados por Rojas, 2014). En efecto, las creencias sobre la carrera docente no solo abarcan la trayectoria en la FID y el ejercicio profesional, sino que también la experiencia como estudiante escolar y en otros roles (apoderada/apoderado, cuidador/cuidadora, madre/ padre, etcétera.) (Perafán, 2016, citado por Fernández y Costillo, 2020). Lo dicho ofrece dos lecturas combinables: las creencias pueden expresar virtudes y problemas ya superados por el tiempo, o fuera de contexto, ignorando desafíos actuales; y/o daría cuenta de una valiosa experiencia acumulada, en consideración a que sintetiza diversos roles escolares, expresando una panorámica longitudinal del sistema educativo.

Por otra parte, además de la experiencia, las creencias se validan por los "consensos culturalmente aceptados" (Rojas, 2014) o conocimientos culturales, evidenciando la influencia del contexto social en el sujeto y, además, la naturaleza intersubjetiva de las creencias (Oliver, 2009, citado por Cortez et al., 2013). Precisamente, las creencias docentes influyen fuertemente en la conducta de sus cercanos. En el caso del vínculo docente-estudiante, las creencias del profesorado pueden configurar — para bien o para mal — el sistema de creencias del alumnado, por ejemplo, "moldeando las expectativas que los estudiantes tienen sobre su propio desempeño en una tarea en particular" (Centro UC Políticas Públicas, 2017a, p. 4).

Un constructo teórico en el PD que se diferencia de las creencias son las concepciones. Mientras las primeras plantean "verdades personales incuestionables", sin mayor sostén que lo experiencial, empírico y afectivo, las concepciones refieren "a marcos organizadores implícitos de conceptos, de naturaleza esencialmente cognitiva y que condicionan la forma de abordar las tareas (...) Una combinación de creencias daría lugar a la concepción" (Donoso et al., 2016, p. 77). Tal como las creencias, las concepciones docentes incorporan elementos de la experiencia y explican las acciones educativas, no obstante, medularmente son producto del razonamiento y comprensión sobre un concepto determinado (Beyer et al., 2019), algo que no 
necesariamente implica la subvaloración de las creencias en el estudio de sus efectos educativos, pues estos no "reconocen" si su origen es más o menos elaborado.

Si bien en el análisis sobre el PD de un grupo determinado podría existir la tentación de enjuiciar críticamente sus creencias y concepciones, en línea con diversos estudios el camino alternativo conlleva una valoración positiva de estas. El PD de un grupo sintetiza — por experiencia acumulada y por absorción de consensos culturales - las necesidades gremiales, territoriales y de desempeño profesional. En un escenario que busca propender a una mayor profesionalización en la carrera docente y dar peso a las demandas del contexto, no es aconsejable la pérdida de un insumo notable acerca de la escuela y quiénes coordinan el trabajo en el aula.

\subsection{Formación Inicial Docente}

A pesar de que el impacto de la FID en el profesorado en formación no es mayor que otros factores, existe evidencia de la relación positiva entre su calidad y la calidad docente en el sistema escolar (Prats, 2016). En procesos rigurosos de FID,

se establecen "las bases de la formación profesional (...). Además, es el primer acercamiento a la práctica real en aula y ofrece oportunidades para reflexionar sobre los desafíos de la docencia y compartir inquietudes con pares. (...) es una experiencia formativa única en tanto los estudiantes ocupan simultáneamente el rol de docente y de estudiante. (Cabezas, Medina, Müller y Figueroa, 2019, p. 5)

La revisión de Cabezas et al. (2019) acerca de la calidad de la FID en Finlandia, Singapur, Australia y Estados Unidos, expone un conjunto de atributos, entre otros:

- Se seleccionan los mejores prospectos, abordando lo académico, lo motivacional, su desempeño grupal, etcétera.

- Se forma para adaptar la práctica educativa a los contextos y necesidades escolares. 
- Se fomenta el pensamiento crítico, la reflexión pedagógica, la mejora continua, la colaboración.

- Se realizan alianzas con las escuelas, bajo una lógica de reflexión y apoyo mutuo.

- Finalmente, se desarrollan prácticas profesionales progresivas, dando un valor importante a la figura del mentor, entre otros.

En las últimas décadas, la FID en Chile ha sido objeto de un mayor control estatal respecto de su calidad, bajo la evidencia de que una formación rigurosa repercute en un profesorado preparado y que este, a su vez, es clave para el aprendizaje escolar (Ávalos, 2014). A pesar de esto, esta formación no ha tenido impacto en el recorte de brechas socioeducativas. Una explicación sería que el profesorado chileno de mejor formación es menos proclive a trabajar en contextos de vulnerabilidad social, en donde están los rendimientos más disminuidos (Cabezas et al., 2019), confirmando lo concluido por Puga, Polanco y Corvalán (2015) acerca de que la FID tiende a reproducir el statu quo de la estructura social chilena, resultando en el futuro en una fuerte relación entre la posición social de origen del docente escolar y el nivel socioeconómico de su alumnado.

Sumado a lo anterior, la FID chilena ha resultado curricularmente homogénea en la preparación del profesorado para su desempeño en contextos diversos (Venegas, 2013; AriasOrtega, Quintriqueo y Valdebenito, 2018), en una muestra de la desvinculación entre escuelas-territorio y universidades (González, Gómez, Ahumada, Bravo, Salinas, Avilés, Pérez y Santana, 2014; García-Huidobro, 2014; Ruffinelli, 2014a; Ferrada et al., 2015; Tenorio, Jardi, Puigdellívol e Ibáñez, 2020).

\subsection{Desarrollo Profesional Docente}

El DPD da cuenta de la trayectoria de aprendizaje del profesorado en la cual la experiencia y la práctica juegan un rol notable. En este camino, cada docente se desenvuelve en un contexto concreto, con variables que afectan su desarrollo y su PD, entre otras: políticas educativas, desgaste laboral, edad, legitimidad profesional, y escenario histórico y territorial de desempeño (Carrasco y Ortiz, 2020). 
En línea con la idea de "trayectoria", García-Huidobro (2014) plantea que "no se llega a ser profesional de la educación en un momento determinado y de una vez para siempre" (p. 66), es un proceso continuo, pero que se distingue de otras profesiones. Según el propio autor, el o la docente "ayuda a otro a hacer", la pedagogía se basa en teorías que no alcanzan la certeza de las ciencias naturales, es una profesión colectiva, la formación continua se facilita con ayuda de pares y congrega conocimientos pedagógicos y disciplinarios. Similarmente, de Medina (2006) se extrae que el desarrollo del profesor redunda en el progreso que otros alcanzan gracias a él, y no en su avance solitario como sujeto profesional, pues su propósito final es mejorar el aprendizaje del alumnado y la gestión de la escuela.

Bajo la lógica actual del DPD como itinerario profesional y formación continua, se instala el concepto de "cultura evaluativa" $y$, con ello, instrumentos y procedimientos formales de valoración de desempeño. En el modelo chileno, devenido en control y rendición de cuentas (Roa, 2017), y con el MBE como referente, se combinan tres tipos de evaluaciones (autoevaluación, coevaluación y heteroevaluación), con sus respectivas complicaciones. Por ejemplo, la autoevaluación, como todo autorreporte, ofrece riesgos de deseabilidad social y distorsión de respuestas, más aún con incentivos por buenos resultados (Roa, 2017; Carrasco y Ortiz, 2020); la coevaluación (entrevista por un par evaluador) resulta en una extensión de la heteroevaluación, al existir una relación de poder del "par" sobre el evaluado, al monopolizar juicio de valor y toma de decisiones.

La evaluación del Estado no es el único enjuiciamiento que afecta la carrera docente. Sobre todo en los principiantes, la valoración informal de la comunidad escolar repercute en la permanencia del profesorado en el sistema escolar (Jennings, 2015, citado por Tenorio, Jardi, Puigdellívol e Ibáñez, 2020). En ciertos casos, también debe enfrentar la disposición de la comunidad por verlo hacer un "apostolado abnegado" (Medina, 2006), o comportándose como un enseñante técnico mas no necesariamente profesional y autónomo (Núñez, 2004, citado por Ruffinelli, 2016). 
Por otro lado, las culturas docentes expresan creencias, valores, normas y hábitos que, entre otros, definen la identidad del profesorado, su trayectoria y sus relaciones (Medina, 2006). Hargreaves (1996, citado por Medina, 2006) da cuenta de cuatro culturas: individualismo, balcanización, colaboración y colegialidad artificial.

El individualismo se asocia al aislamiento profesional, aunque no está carente de interacción operativa entre pares o acuerdos domésticos. La balcanización responde a la conformación, espontánea o formal, de subgrupos de docentes en el establecimiento, que se aíslan y rivalizan entre sí, fundamentalmente para lograr posiciones privilegiadas. La colaboración, esto es, relaciones constantes, abiertas, de apoyo, espontáneas y voluntarias entre docentes comprometidos en la mejora del establecimiento. Finalmente, la colegialidad artificial expresa relaciones forzadas, dispuestas administrativamente por el establecimiento o el Estado para obligar a la colaboración, significando un funcionamiento individual y una colaboración aparente.

En el contexto de la cultura docente, y promovido por la política pública, se ha identificado el uso desacertado del concepto de "autonomía docente", al igualarlo con la capacidad de cada docente para responder individualmente a las obligaciones del sistema educativo (Contreras, 2018). Tal hecho ha derivado en culpabilización por los resultados, individualismo y sobrecarga laboral (Figueroa y Cavieres, 2020). Evidencias de este aislamiento se encuentran en el estudio internacional TALIS 2013 (citado por Ruffinelli, 2016), al reportar que el $40 \%$ del profesorado chileno nunca ha asistido a una reunión de trabajo con sus colegas de escuela, y que la mayoría encuestada nunca ha participado en observaciones de clase de sus pares.

\section{Metodología}

El presente es un estudio cualitativo, con un diseño tipo revisión sistemática, que busca consolidar la evidencia científica generada a partir de un objeto de estudio, en este caso, el pensamiento docente (Ramírez, Meneses y Floréz, 2013; Hederich, Martínez y Rincón, 2014). 
De octubre de 2019 a marzo de 2020 se indagó en reportes, artículos e informes de investigación, consultando en bases de datos (BEIC, ERIC, WOS) y en el catálogos de artículos disponibles en páginas web de revistas científicas chilenas, Agencia de Calidad de la Educación, ACE, Consejo Nacional de Educación y Ministerio de Educación. Los términos de búsqueda utilizados, en español y traducidos al inglés, fueron: "creencia", "docente", "percepción", "teoría implícita", "teoría subjetiva", "escuela", "liceo", "profesores", "profesorado", "pensamiento docente" y "Chile".

Como periodo de búsqueda se definió el lapso 2011-2019, al corresponder a una etapa prolongada, sin perturbaciones excepcionales, como la pandemia por covid-19 (2020-2021), que abarca un sistema escolar administrado por dos gobiernos de distinta tendencia política y que contempla la aprobación de las leyes del Sistema Nacional de Aseguramiento de la Calidad de la Educación Parvularia, Básica y Media y su Fiscalización ( $N^{\circ} 20.529$, 2011), y de Carrera Docente.

Cada investigación debía, por un lado, relacionarse con el objeto de estudio de este trabajo y situarse en el contexto escolar chileno, y, por otro, responder a uno de los siguientes criterios de elegibilidad:

a) Investigaciones sometidas a arbitraje científico.

b) Investigaciones de entidades privadas con financiamiento público.

c) Investigaciones de instituciones públicas.

Excluyendo resultados de tesis, tesinas e investigaciones de pregrado, se halló setenta fuentes de información, seleccionándose finalmente treinta y cuatro vinculadas con el objeto de estudio y las categorías: Becerra y Flores (2011); Vergara (2011); Ávalos y Sotomayor (2012); Ferrada y Turra (2012); Castro, Agüero, Barraza, Escobar y Jorquera (2012); San Martín (2012); Sisto (2012); Ruffinelli (2013, 2014a, 2014b); Fardella (2013); OCDE (2014, 2019); Guzmán (2013); Flores (2014); Morales et al. (2014); Díaz (2015); Fardella y Sisto (2015); Muñoz, López y Assaél (2015); Miño (2016); Salinas, Oller y Muñoz (2016), Centro UC Políticas Públicas (2016, 
2017b, 2018), ACE (2018a; 2018b); Hernández, Pavez, González y Tecpan (2017); Tapia y Cubo (2017); Barraza y Leiva (2018); Pascual y Navío-Gámez (2018), Garay y Sillard (2018); Acuña, Contreras y Assaél (2019); Gelber, González, Escribano y Ortega (2019); Sepúlveda et al. (2019).

La selección se configuró con 52,9\% de estudios cualitativos, $41,2 \%$ cuantitativos y $5,9 \%$ estudios mixtos, distribuyéndose respecto del año de publicación del siguiente modo: 5,9\% de 2011, 14,7\% de $2012,11,8 \%$ de $2013,11,8 \%$ de $2014,8,8 \%$ de $2015,8,8 \%$ de 2016 , $11,8 \%$ de $2017,17,6 \%$ de 2018 , y $8,8 \%$ de 2019 . En los estudios seleccionados participaron aproximadamente 52.730 docentes escolares chilenos. Dos fuentes de información no cuantificaron su muestra.

Previamente se levantaron siete categorías apriorísticas para el estudio: Formación Inicial Docente, Apoyo al desarrollo profesional docente, Evaluación del desempeño profesional, Valoración de agentes externos del desempeño docente, Ambiente laboral y profesional, Condiciones de trabajo y productividad, y Liderazgo y gestión del equipo directivo.

Estas categorías se basan en dos líneas que se consideran vitales en las políticas docentes. Por un parte, los procesos de aprendizaje profesional, formación y evaluación del desempeño (FID, DPD, Evaluación Docente y valoración externa), y, por otro, los contextos profesionales de desempeño (condiciones de trabajo y relaciones con pares y directivos). Estos últimos, comúnmente invisibilizados, interfieren y complejizan la carrera (Carrasco y Ortiz, 2020; Tenorio et al., 2020).

\section{Resultados}

Los resultados se presentan según las categorías apriorísticas anunciadas. En cada categoría o apartado los estudios han sido agrupados, primero, de acuerdo con su naturaleza metodológica (cuantitativo, cualitativo o mixto) y luego cronológicamente. 


\subsection{Formación Inicial Docente}

En el contexto de los estudios cuantitativos, en Ruffinelli (2013) los docentes noveles destacan como aporte de la FID a su aprendizaje, independiente de su institución formadora y el modo de ingreso a la carrera, lo pedagógico (curriculum y evaluación), el manejo de estudiantes y las habilidades blandas y de adaptación al establecimiento escolar. Por el contrario, aparecen como necesidades formativas: la didáctica en segundo ciclo básico $\left(5^{\circ}\right.$ a $\left.8^{\circ}\right)$, la didáctica de las ciencias sociales y naturales, los conocimientos disciplinarios de ciencias sociales y la expresión oral y escrita.

En tanto, en otro estudio de Ruffinelli (2014a), al momento de atribuir sus fortalezas profesionales solo el $10 \%$ de los encuestados lo hace a favor de su FID y, en cuanto a la atribución de sus dificultades, no más del $20 \%$. No obstante lo anterior, se presenta un porcentaje importante de docentes de tres años de experiencia o menos que está satisfecho con lo recibido en su FID (85\%), y que se considera preparado para ejercer profesionalmente (94\%). Así también el 72\% de ellos considera que su formación se ajustó a las demandas reales de su ejercicio profesional.

Estos resultados son similares a los obtenidos por Garay y Sillard (2018), con docentes de diversas edades y experiencias, exceptuándose la preparación en el uso de las TIC, en que un 56\% la consideraba regular o malo. Llamativamente, al separar los resultados por edad se observa que el grupo de 41 años o más tiene una opinión mayormente positiva sobre su FID respecto del grupo de 40 o menos.

En relación con trabajos cualitativos, en Ávalos y Sotomayor (2012) se expone que la valoración que el profesorado hace de la FID -en evaluación, planificación de clases, uso de TIC y comprensión de contenidos curriculares- decrece a medida que se adquiere experiencia profesional, contrariamente a lo que ocurre con las actividades de formación continua, en que la "estima" aumenta con los años. Según el profesorado, la FID disminuye su impacto formativo con el tiempo, siendo reemplazada por la experiencia adquirida como fuente para solucionar dificultades. 
En Ferrada y Turra (2012) se busca recoger el aporte del saber acumulado del profesorado de contextos "urbanidad marginal" e "indigeneidad", para luego ser sistematizados en una propuesta curricular para la FID. En sus resultados, los participantes dan cuenta de la necesidad de contextualizar la FID a distintas realidades, cuestionando su homogeneidad, diversificando los programas de formación según requerimientos particulares (fundamentalmente en contextos de vulnerabilidad) "fuertemente anclado al carácter demográfico cultural del contexto..." (p. 214).

En este mismo sentido, los requerimientos específicos del contexto "urbano marginal" están "a nivel de diseño de praxis curricular". Se precisa que diseño y desarrollo se integren en relación con

los contextos de desempeño laboral; con nuevos contenidos a nivel de la especificidad cultural asociada, dados por el propio contexto de vulnerabilidad; con nuevas demandas de apoyo pedagógico por parte de los apoderados y de redes de colaboración de agencias sociales de la comunidad; y los nuevos requerimientos de formación a nivel de prácticas progresivas que adquieren la exigencia de hacerlas permanente e intensivas en los contextos de vulnerabilidad específicos de desempeño. (Ibíd.)

En tanto, en el contexto de "indigeneidad" las necesidades se posicionan fundamentalmente en "la mantención de la cultura y la lengua", a través del trabajo con apoderados y familias, la gestión comunitaria y el establecimiento de redes de apoyo.

Por su lado, Guzmán (2013) aborda la visión de los "profesores ejemplares"2. Estos valoraron favorablemente su FID, declarando que les entregó herramientas concretas de planificación, de didáctica y evaluación en favor del logro de aprendizajes. Especialmente, "la mayoría puso el acento en el vínculo afectivo que establecieron con algunos profesores universitarios" (p. 844).

2 Corresponde a un grupo de docentes que, en el contexto del estudio, fueron positivamente evaluados por sus estudiantes y colegas del establecimiento, y como "destacados" y "competentes" en la Evaluación Docente. 
En Flores (2014), más de la mitad de los docentes novatos indagados coincide en que sus tareas profesionales han resultado más demandantes y complejas que lo previsto. Culpan a los planes de estudio de su FID "por no entregarles una preparación adecuada acorde a la realidad de un profesor con carga horaria completa" (p. 45), develando la existencia de un contrapunto entre laboratorio-FID y el campo-ejercicio profesional.

Similarmente, en Díaz, Solar, Soto y Conejeros (2015) se muestra que una gran demanda en el profesorado es la correspondencia entre contexto escolar y formación inicial: nueve de cada diez docentes considera que las universidades deben acercarse al establecimiento para conocer las necesidades reales de formación de los docentes.

Por último, en Tapia y Cubo (2017) el profesorado participante estima como imprescindible la formación temprana en habilidades conversacionales (escuchar, conversar, comunicación, hablar y diálogo), habilidades para compartir (sociabilidad, amistad, relación, convivencia y participación) y habilidades empáticas y solidarias (empatía, solidaridad, ayuda, tolerancia, comprensión y confianza).

\subsection{Apoyo al desarrollo profesional docente}

En relación con los estudios cuantitativos, 1.676 docentes chilenos participaron en 2013 en el estudio TALIS. El carácter global de la encuesta permitió el contraste entre el pensamiento docente chileno y el internacional, por ejemplo, sobre la participación en actividades de desarrollo profesional (formación continua, perfeccionamientos) en el último año. Si el promedio de los países participantes es de 88\%, los docentes chilenos alcanzan al 72\%, muy lejos del de Singapur (98\%). Para justificarlo, el profesorado chileno aduce falta de incentivos, oferta de "cursos" poco relevantes y bajo apoyo de los "empleadores" (OCDE, 2014).

En el mismo trabajo el profesorado opinó que la oferta de formación continua era poco relevante. Su principal requerimiento es la enseñanza en contextos de diversidad: enseñanza a estudiantes con necesidades educativas especiales, $26 \%$, y enseñanza en entornos 
multiculturales, 22\%. Cinco años después, en TALIS se insiste en una "mayor necesidad de capacitación en la enseñanza para estudiantes con necesidades educativas especiales" (p. 4). Estos requerimientos profesionales para la formación continua confirman los hallazgos previos de San Martín (2012), a la vez que son reafirmados más tarde en las investigaciones "Tarea de Todos. Hacia una visión compartida de la calidad de la educación", a cargo de la ACE (2018a) y en Gelber et al. (2019).

Respecto de cómo se seleccionan los cursos de formación continua/perfeccionamiento, en Díaz et al. (2015) el 56\% del profesorado consultado afirma que estos son escogidos por el establecimiento, según un diagnóstico de necesidades docentes. La propia investigación plantea que, a pesar del "impacto positivo" de los programas de perfeccionamiento, solo la mitad del profesorado considera que estos son de "buena calidad" cuando son impartidos por universidades, entendiéndose que cuando los cursos son ejecutados por entidades de Asistencia Técnica Educativa, ATE, consultoras y especialistas particulares, sí lo son. A mayor abundamiento, las relaciones entre el profesorado escolar y las universidades se observan tibias e irregularmente productivas, pues solo el $42 \%$ estima que este vínculo fortalece el proyecto educativo del establecimiento.

Sobre las fuentes de actualización docente, aunque en un ámbito bastante específico, en Salinas et al. (2016) los medios utilizados por el profesorado para educar en ciudadanía son libros de texto (31\% de investigados), textos de educación cívica (16\%), páginas de internet (15\%), actual Constitución política chilena (13\%), contenido curricular (12\%), prensa (9\%) y "realidad social" (3\%). Esto evidenciaría, muy preliminarmente, que, según la temática, las fuentes varían, sin que el rigor conceptual sea preocupación transversal.

Por otra parte, la encuesta "Voces Docentes II" de 2016 expone que más del 90\% del profesorado considera que las instancias de perfeccionamiento son recurrentes y, de acuerdo con sus creencias, tienen un impacto importante en su formación en función del aprendizaje de sus estudiantes y su sensación de confianza para 
identificar fortalezas y áreas de mejora (Centro UC Políticas Públicas, 2017b, p. 7).

Dos años después TALIS 2018 evidencia una tendencia de participación regular en procesos de formación continua. El 87\% de docentes afirma asistir, como mínimo, a una actividad anual de formación, siendo las más habituales los cursos y seminarios (57\%), frecuentemente sobre aprendizaje escolar y observación entre pares (46\%). La percepción de un impacto positivo de las actividades de desarrollo profesional se repite (77\%). Este mismo grupo de docentes muestra altos niveles de autoeficacia y satisfacción laboral (OCDE, 2019). Los resultados previos de Díaz et al. (2015) se replican en TALIS 2018.

En Barraza y Leiva (2018) se devela que la principal fuente de actualización sobre los tópicos de aprendizaje y neurociencia es internet y las redes sociales (21\%). Luego aparecen los programas de televisión "por cable" (14\%), las capacitaciones gestionadas por el establecimiento (13\%) y la información proporcionada por el Ministerio de Educación. De esto, resulta llamativo que un tercio de los docentes se "renueve" y aclare las dudas mediante fuentes de información alejadas de lo profesional y científico.

Por último, desde una perspectiva cualitativa y previo a la aprobación de la ley de Carrera Docente (2016), que estableció un sistema de inducción del profesorado novel a la escuela, Ruffinelli (2014b) estudia la visión de este tipo de profesorado en dicha etapa. Se informa que los docentes novatos, al solicitar colaboración a su jefe directo o a sus pares, son regularmente apoyados informalmente, quedando dicha ayuda relegada a la "buena voluntad". "[Estos son] casos sugerentes de ausencia de instancias colaborativas" (p. 63), por lo que habría una tercera salida para el principiante: solucionar los problemas en forma solitaria. A su vez, Flores (2014) llega a un hallazgo similar. Se identificó un ambiente de soledad y falta de apoyo, dada la falta de consejos y retroalimentación en el establecimiento sobre las prácticas de aula. 


\subsection{Evaluación del desempeño profesional}

Primeramente, en la investigación cuantitativa "Voces Docentes" (CUCPP, 2015) se aborda la posición del profesorado respecto de cómo debería ser evaluado en el contexto de la Carrera Docente. En orden decreciente, las preferencias son: autoevaluación (87\%), evaluación por superiores del establecimiento (80\%), evaluación de prácticas en el aula a nivel nacional (74\%), evaluación de un par del establecimiento (69\%) y evaluación de conocimientos disciplinares a nivel nacional (57\%).

Ese mismo año, en Díaz et al. (2015), 87\% de los encuestados cree que la evaluación que realmente permitiría mejorar el desempeño sería una que se emarcara en el análisis de la práctica docente del evaluado, desechando por ello instancias como las pruebas de conocimientos pedagógicos y de la disciplina.

Mas tarde, "Voces Docentes III" (CUCPP, 2018) recoge que tres cuartas partes de los docentes consultados considera necesario evaluar el desempeño en el contexto de la Evaluación Docente y del Sistema de Reconocimiento (Ley de Carrera Docente). Aunque esta disposición favorable disminuye al 50\% de los consultados sobre si creen que los resultados de las evaluaciones favorecen la mejora pedagógica del docente evaluado.

En relación con estudios cualitativos, en Sisto (2012) los investigados consideran a la Evaluación Docente como un instrumento de culpabilización al profesorado, invisibilizando la presencia de otros factores, y se critica la subjetividad de la evaluación y el desconocimiento del contexto de parte de quienes diseñan y evalúan.

En tanto, en Fardella (2013) se advierten prácticas que deslegitiman el proceso de evaluación docente, por ejemplo, la "puesta en escena" para la filmación de la clase, uno de los procedimientos de la evaluación:

Muchos profesores relatan maquillarse, ordenar la sala, tenerla lista o preparada, disponer de ciertos recursos audiovisuales o 
materiales didácticos que no son usados en contextos ordinarios. La escena implica la construcción de un setting, aquellas cosas propias del trasfondo escénico. Se relata tener todo preparado, arreglado, dispuesto para una actuación particular para montar un guion, donde se desarrollan ciertos modales, conductas y actitudes que reflejen coherencia con la atmósfera creada. (p. 87)

Otra práctica deslegitimadora del proceso es la compra de portafolios, excusada por la presión social de lograr un buen resultado: "En caso de resultar mal evaluado el profesor corre el riesgo de perder su trabajo. De acuerdo a esto, comprar el portafolio consiste en pagar terceros por la realización de este" (Fardella, 2013).

Por su parte, en Fardella y Sisto (2015) es observable cómo los docentes incorporan la clasificación de su desempeño a su propia identidad como docente: "...frases como 'es que soy básico' (E19MascADB:15) 'usted es un profesor competente' (E14FemNDC:1) resultan características del corpus, apareciendo en la totalidad de las entrevistas realizadas" (p. 73). El profesorado se etiqueta a sí mismo con el resultado de su evaluación, asumiendo luego, presumiblemente, las actitudes atribuidas a dicha etiqueta.

En Fardella y Sisto también se manifiesta que, según el profesorado, las evaluaciones docentes no reflejan la práctica del educador como tal o, como plantean los mismos investigadores, "no permiten mostrar la versión de ejercicio profesional que el docente quiere mostrar de sî" (p. 76).

A su vez, en Sepúlveda et al. (2019) el profesorado con mal resultado en la evaluación docente considera que la retroalimentación recibida no es clara, por lo que tiene poca utilidad. Además, justifican su desempeño con la soledad en que asumieron la instancia, sin asesoría de pares ni el apoyo de sus escuelas y directivos, con exceso de confianza y, contradictoriamente, una serie de inseguridades de diverso tipo. Aseguran que los resultados obtenidos no reflejan su quehacer en el aula, el que sería de mayor calidad; aunque les preocupa que la comunidad se quede solo con lo logrado en la evaluación, afectando su imagen y autoestima. 
En el mismo estudio el profesorado mal evaluado se queja de que la evaluación no considera ni su realidad laboral, ni las limitaciones del contexto, ni el estudiando diverso, ni las condiciones de vulnerabilidad. Por ello, dan escasa confiabilidad y objetividad a los instrumentos de evaluación aplicados.

\subsection{Valoración de agentes externos del desempeño docente}

En la sección cuantitativa del estudio de Ávalos y Sotomayor (2012) aparece la idea docente de que muchas de las decisiones que afectan al profesorado son tomadas fuera de la escuela, "sin conocer la realidad ni comprender la dureza del día a día con los estudiantes" (p. 78). En la encuesta resulta habitual cuestionar la distancia entre el profesorado y los gestores del Estado, quienes definen las políticas y exigen resultados. Este cuestionamiento tiene coincidencias en los trabajos cualitativos de Sisto (2012) y Sepúlveda et al. (2019).

Por su parte, en el estudio cuantitativo de Hernández et al. (2017) el profesorado percibe una valoración favorable de sus estudiantes y la comunidad educativa en general, sin embargo, estiman un bajo reconocimiento de sus capacidades por parte de la sociedad y el Estado. Los autores lo explican por la disminuida compensación económica recibida por su trabajo, de forma que el profesorado traduciría el valor social de la profesión en el sueldo obtenido y su consecuente calidad de vida. Así se podría entender por qué, "si bien los profesores volverían a estudiar pedagogía, no lo recomiendan para sus estudiantes y aún menos para sus hijos" (p. 443).

\subsection{Ambiente laboral y profesional}

En el trabajo mixto (cualitativo-cuantitativo) de Ávalos y Sotomayor (2012, p. 79) se observa con regularidad que el profesorado principiante valora el apoyo y experiencia de los docentes con mayores años de ejercicio, situándolos como una "fuente de aprendizaje práctico", es decir, como referentes para sostener su menor grado de seguridad profesional. Respecto del ambiente profesional, se devela 
que el profesorado con desempeño en colegios privados se siente mayormente demandado en cuando a la calidad educativa y al modo en que "desafía" a sus estudiantes, es decir, qué tan exigentes son con estos.

Sobre las relaciones sociales entre docentes de un mismo establecimiento, el trabajo de Morales et al. (2014) arroja que el $17,2 \%$ de los profesores encuestados dice haber sido ridiculizado o humillado por un colega "en el último mes". Más aún, el 35,1\% afirma haber sido testigo de estas acciones. En cuanto a la interacción entre profesorado y directivos, las cifras no disminuyen: 16,9\% de docentes declara haber sido ridiculizado o humillado por un directivo, al menos una vez durante el último mes, y un 9,4\% haber sido amenazado. Los encuestados que han observado humillaciones se congregan en un $27,3 \%$, y un $14,7 \%$ afirma haber presenciado amenazas.

Por su lado, TALIS (Teaching and Learning International Survey) (OCDE, 2019) permite confirmar el hallazgo ya mencionado de Ávalos y Sotomayor (2012). El 72\% de docentes "reportan que ellos y sus colegas se apoyan mutuamente en la implementación de nuevas ideas" (OCDE, 2019, p. 3), aunque es un porcentaje bajo respecto de otros países de la OCDE.

Por otra parte, actividades no muy estudiadas son los consejos de profesores. Acuña et al. (2019) conducen un estudio etnográfico sobre las interacciones en estas reuniones, dando cuenta de un fenómeno denominado "monólogo en los consejos de profesores". Se patentiza "el nivel de burocratización del espacio; la verticalidad en el uso de la palabra y las decisiones sobre qué se puede decir y qué no se puede decir; y el silencio de los docentes" (p. 4). Este silencio en un espacio dirigido a la discusión pedagógica es justificado por docentes y directivos en sentidos opuestos. Mientras el profesorado argumenta, por ejemplo, que el silencio es efecto del miedo a perder el empleo, el equipo directivo sostiene que todo se debe a la inseguridad de los docentes. 


\subsection{Condiciones de trabajo y productividad}

Sintéticamente, en los estudios nacionales sobre esta temática aparece recurrentemente la idea de "sobrecarga", asociada al desacople entre tareas docentes y tiempo disponible para cumplirlas.

Desde un enfoque mixto cuantitativo-cualitativo, Becerra y Flores (2011) investigaron acerca del desgaste o burnout docente en un contexto de prejuicio étnico en Chile. Sus conclusiones establecieron una relevante "sintomatología de burnout" del profesorado a partir de su discurso: "Se constatan altos niveles de cansancio emocional y falta de realización profesional en los participantes, revelando elevada incidencia de desmotivación de los docentes frente al quehacer profesional" (p. 32). Tal situación se gatillaría en el aula, entre otras razones, por "la percepción de las difíciles condiciones de educabilidad y altas necesidades psicosociales de los estudiantes indígenas, al mismo tiempo que se evidencia la percepción de falta de formación profesional y sentimientos de inhabilidad docente para responder a tales condiciones y necesidades" (p. 33). Lo interesante es que esa percepción de "difíciles condiciones de educabilidad" no sería necesariamente real, sino que parte de un prejuicio hacia el estudiantado mapuche, significando que el profesorado "produciría" su propio agobio y desgaste. Asimismo, habría factores externos al aula que repercutirían en el burnout docente: "las carencias de materiales e infraestructura, la multifuncionalidad del rol, la falta de apoyo al rol docente, y el desinterés de las familias" (p. 34).

En la encuesta TALIS 2013 el profesorado nacional informó "pasar menos horas a la semana poniendo notas y/o corrigiendo el trabajo de los estudiantes que en la mayoría de los demás países participantes (4 horas vs. 5 horas promedio TALIS)" (Centro de Estudios Mineduc, 2015, p. 4). En relación con el trabajo con padres y apoderados, los participantes declaran dedicar dos horas a la semana, siendo un periodo mayor al que emplean en promedio los demás países. Sobre el tiempo dedicado a la enseñanza en el aula, Chile es uno de los países con menor porcentaje (cuarto lugar, 74\%). En la comparación, Finlandia presenta un 80,6\%. Los docentes chilenos "reportan dedicar más tiempo de clases a tareas administrativas y a mantener el orden en aula" (p. 4). 
Por otro lado, en Morales et al. (2014) docentes de educación municipal revelan ser víctimas o testigos de agresiones de estudiantes a profesores en una cantidad importante, mediante groserías, robo, destrucción de pertenencias, empujones, golpes, generación de heridas y amenazas de agresión.

La victimización del profesorado, por acción de familiares y apoderados de estudiantes, incluye la amenaza, la ridiculización y la humillación; el porcentaje de presencia no baja del 20\% cuando el docente declara ser "víctima" de estas acciones. Los docentes "testigos" de estas agresiones son muchos más:

El 58\% de los profesores participantes del estudio declararon haber observado que un apoderado amenazara a otro profesor (...). El 42,3\% señaló haber presenciado situaciones de humillación o ridículo ejecutadas por apoderados a un colega (...). El 17,9\% en tanto, indicó haber visto agresiones físicas de parte de apoderados a otros profesores en el último mes, mayoritariamente con frecuencia de una o dos veces. (Morales et al., 2014, p. 106)

Por su parte, en Miño (2016), el profesorado asegura tener "una alta carga de trabajo, manifestada en falta de tiempo para la vida personal, cantidad de trabajo, estrés, prisas y agobios, carga de responsabilidad, baja satisfacción con el sueldo y dificultad para desconectarse al acabar la jornada de trabajo" (p. 45). Los datos de este estudio cuantitativo son coincidentes con el trabajo cualitativo de Guzmán (2013).

Con relación a lo identificado en estudios cualitativos, en Vergara (2011) el profesorado fundamenta en las exigencias administrativas de la escuela y la falta de tiempo el mantenimiento de rutinas evaluativas contrarias a la literatura pedagógica y científica.

En Castro et al. (2012) los docentes afirman que el agobio laboral y profesional impide participar en forma activa y motivada en las actividades de reflexión en el establecimiento y en las capacitaciones. Coherentemente, en Muñoz et al. (2015) expresan que la falta de tiempo para trabajar conjuntamente entre docentes 
de educación básica y de educación especial afecta precisamente los procesos de inclusión escolar.

En Pascual y Navío-Gámez (2018), profesoras y profesores justifican el uso de planificaciones "antiguas" debido a la sobrecarga de trabajo, "dejando poco tiempo para la reflexión e institucionalización de las innovaciones que se improvisan en el aula" (p. 85). Esto se vincula a lo ya indicado en Vergara (2011).

Finalmente, en el estudio "Tarea de Todos" (ACE, 2018a) los investigados afirman que la falta de tiempo y condiciones laborales y educativas de las escuelas (horas de clase, masividad de aula, salarios, entre otras) son barreras para atender a la diversidad y adaptarse a las necesidades del estudiantado.

\subsection{Liderazgo y gestión del equipo directivo}

En la investigación cuantitativa de Miño (2016) los docentes consideran que el apoyo recibido desde los directivos es adecuado, pudiendo indicar que, aunque poco formal e incluso verticalista, el docente es acompañado en términos aceptables. Sin embargo, en función de la dependencia de la escuela, la intensidad de éste varía. Los docentes de establecimientos municipales "experimentan un mayor apoyo por parte de sus superiores en el desempeño de sus funciones" (p. 45) respecto del profesorado de instituciones particulares.

En "Voces de los docentes"3 de la ACE (2018b) se utilizan los resultados del cuestionario de Calidad y Contexto de 2017, respondido por docentes de $4^{\circ}$ y $8^{\circ}$ básico, y de $\mathrm{II}^{\circ}$ medio (casi cuarenta mil sujetos), cuyos estudiantes rindieron la prueba SIMCE. La información recogida señala que, según el profesorado, la prioridad de la gestión directiva de sus establecimientos está en la formación académica (50\%) y, en segundo plano, en el desarrollo personal y social de los estudiantes (30\%). En cuanto a la presencia "clara" de lineamientos y orientaciones para la enseñanza y la evaluación en el establecimiento, ocho de diez docentes se manifiestan de acuerdo.

3 No confundir con "Voces docentes" de Elige Educar y el Centro UC de Políticas Públicas. 
Aquí el resultado más alto se encuentra en el profesorado de las escuelas particulares pagadas.

Finalmente, en el estudio cualitativo de Sepúlveda et al. (2019) el profesorado con mal resultado en la evaluación docente asegura sentirse poco apoyado por sus directivos durante el proceso, por ejemplo, al no reservarle tiempo para preparar la instancia.

\section{Discusión y conclusiones}

Las principales conclusiones de este estudio de revisión sistemática se expresan a continuación, según cada categoría.

Sobre Formación Inicial Docente, las investigaciones cuantitativas evidencian opiniones favorables de la preparación de la FID para la vida profesional; no obstante, al plantear sus fortalezas y debilidades, estas no son atribuidas al pregrado, complicando dimensionar el real impacto de este proceso en el profesorado. Además, se observan contradicciones entre los estudios sobre la valoración de la FID y el avance en la experiencia profesional, lo que se explicaría por la disparidad en la calidad formativa que recibieron los investigados. Así, el mayor control en la acreditación de los programas de pedagogía, debido a la ley de Carrera Docente, aparece como algo acertado. Una de sus expresiones son los estándares pedagógicos y disciplinarios (hoy en actualización) cada vez más vinculantes a los procesos de acreditación.

En los resultados cualitativos, los sujetos son más críticos con su FID, manifestándose una alta demanda por desarrollar el vínculo universidad-escuela. Esto coincide con Ferrada, Villena y Turra (2015) y se conecta con la política actual que ha relevado la inmersión en la escuela del docente en formación, al establecer como criterio de acreditación de las carreras pedagógicas la existencia de convenios entre universidades y establecimientos. Sin embargo, esta alianza ha sido permanentemente compleja y atesora resistencias significativas, expresadas recíprocamente en suspicacias, inseguridades y subestimaciones (Garay y Sillard, 2018; Tenorio et al., 2020).

Respecto del Apoyo al desarrollo profesional docente, cuantitativamente se plantea una participación significativa en 
instancias de formación continua, impactando en el desempeño, aunque aparecen quejas por falta de incentivos y de colaboración del sistema y los empleadores, y por las temáticas abordadas que no satisfacen sus necesidades. También, hay desconfianza en la calidad de los perfeccionamientos ofrecidos por las universidades, confirmando una relación difícil entre estas y la escuela-profesorado (Tenorio et al., 2020). Por esto, probablemente, un grupo no menor prefiere actualizarse mediante internet y redes sociales, aunque en los trabajos cualitativos aparecen otros recursos más tradicionales.

Visto esto, una de las principales barreras para el DPD es la contribución al agobio laboral que suponen perfeccionamientos y postítulos, al no reservar tiempo y espacio al profesorado para su cumplimiento, desde el Estado y los empleadores. Según Roa (2017), toda política de DPD debiese abordar dos propósitos: "Definir y propiciar cursos de acción para fortalecer la profesión, su expertismo y estatus a lo largo de toda la carrera, a la vez que fortalecer las condiciones del ejercicio concreto orientado a la mejor enseñanza" (p. 46). Así, la política debe considerar tanto el insumo formativo o de desarrollo, como las condiciones adecuadas para su aprovechamiento docente.

Sobre la Evaluación de desempeño profesional, el profesorado estima necesario desarrollar dicho proceso, pero cuestiona su aplicación. Aduce que no favorece la mejora, que tiene poca utilidad, que no refleja su real desempeño profesional, que ignora el contexto social y educativo de desempeño (Carrasco y Ortiz, 2020), que no recibe ayuda en su realización, que es "subjetiva" y que se usa para culpabilizarlos (Figueroa y Cavieres, 2020). Quieren dar más relevancia a la autoevaluación, a pesar de su "deseabilidad social" (Roa, 2017), y a la heteroevaluación de sus superiores; también demandan mayor atención en sus prácticas que en sus conocimientos pedagógicos y disciplinares. Aunque también deambulan entre el exceso de confianza y la inseguridad profesional durante la evaluación (Wilhelm, Martin y Miranda, 2012). Finalmente, les preocupa la reacción de la comunidad escolar frente a sus resultados; algunos confiesan prácticas deshonestas para realizar una buena evaluación. 
La evaluación docente ha sido objeto de voluminosas críticas desde el profesorado chileno, debido a su desatención por lo formativo y a priorizar la rendición de cuentas y la responsabilización (Roa, 2017). En tal escenario, dado que el carácter de la evaluación condiciona la disposición de los sujetos frente al proceso (Casanova, 2019), el profesorado evaluado actúa en función de los resultados necesarios para responder al sistema, transformando el contexto en un escenario artificial y las interacciones didácticas evaluadas en circunstancias poco reales. Así, la evaluación pierde toda validez. Complementariamente, el trabajo de Santelices, Galleguillos, González y Taut (2015), cruzando datos del SIMCE y de la evaluación docente, determinó "la dificultad de medir el desempeño de un docente separado del contexto en el que se desempeña" (p.12). Sugiere incluir apropiadamente al contexto en el proceso de evaluación.

Por último, dada la connotación negativa de la evaluación docente en el profesorado investigado y en el sistema chileno, por su orientación a la rendición de cuentas (Carrasco y Ortiz, 2020), resulta cuestionable la obligatoriedad de su aplicación a los docentes de la educación pública y particular subvencionada, y su excepción a quienes se desempeñan en establecimientos privados. Esta política significa una carga social desigual para quienes aparecen cuestionados, a través de una evaluación profesional, situando el peso de la prueba de calidad en un solo grupo (Fardella, 2013).

En relación con la Valoración de agentes externos del desempeño docente, el profesorado piensa que es positiva desde la comunidad educativa, algo que, según Jennings (2015, citado por Tenorio et al., 2020), impactaría favorablemente en su permanencia en el sistema escolar. Contrariamente, consideran que esta buena opinión no es compartida ni por la sociedad ni por el Estado, lo que grafican en que las decisiones y políticas educativas son tomadas externamente, sin considerarlos, en especial en la adhesión de sus demandas a las políticas de FID (Ferrada, 2017).

Al respecto, Hernández et al. (2017) aventuran que la desvaloración docente puede explicarse por los constantes cambios en el sistema educativo chileno y cierta incapacidad del profesorado 
para adaptarse a las innovaciones del sistema. Expresaría esto que el estatus docente, como construcción social, es sensible al tiempo y está afecto al contexto. En consecuencia, no se podría esperar que el aprecio social por el profesorado de mediados del siglo XX se mantenga invariable hasta hoy. Si los tiempos cambian, las variables de la valoración social del magisterio también.

En tal sentido, es innegable que el profesorado, lejos de la pasividad, tiene responsabilidad en la imagen que la sociedad tiene sobre él, aunque evidentemente, no la única. El Estado exhibe gestos que contribuyen a la desvalorización, por ejemplo, en la ausencia de profesionales de la educación en los puestos técnicos protagónicos, como es el Ministerio de Educación: desde 1990, de veinte ministros de educación solo tres han sido profesores.

Acerca del Ambiente laboral y profesional, la información cuantitativa y mixta evidencia que, en lo pedagógico, existen interacciones generalmente favorables en las escuelas, incluso colaborativas, dando cuenta de la identidad colectiva de la profesión docente (Medina, 2006; García-Huidobro, 2014), a pesar de que aparecen situaciones de "ridiculización" y hostigamiento de colegas y directivos. Por otro lado, en escuelas privadas se sienten altamente presionados (Cornejo et al., 2015). Cualitativamente se evidencia una participación pasiva en ciertas instancias, probablemente por subyugación al poder del equipo directivo, e indiferencia, en un sentido de colegialidad artificial (Hargreaves, 1996, citado por Medina, 2006), en que cada sujeto se comporta "solidariamente" en la medida en que sus pares permiten lograr su objetivo particular, muy en la línea de una acción estratégica levantada por Habermas (2007). Aquí surge un desafío paradójico para la política docente, por cuanto debe promover entusiastamente la colaboración profesional, pero sin traspasar la delgada línea entre la colegialidad genuina y la coacción.

Sobre las Condiciones de trabajo y productividad, la "sobrecarga de trabajo" (Figueroa y Cavieres, 2020) y el "agobio laboral" emergen permanentemente en el pensamiento docente. Acusan, por ejemplo, dedicar más tiempo a tareas administrativas que a la acción pedagógica, llevándolos a usar tiempo personal para responder a las 
demandas profesionales, a planificar superficialmente y a no participar en instancias de reflexión y desarrollo profesional. Mediante la ley de Carrera Docente la política pública se ha encargado parcialmente del agobio laboral, modificando la relación entre horas pedagógicas lectivas y no lectivas. Estas últimas aumentaron de 25\% a 35\% de las horas contratadas.

A este desgaste se suman incidentes (agresiones) con estudiantes y familias, algo que un estudio previo de Morales et al. (2014) atribuye al carácter "clientelar" que ha asumido la familia respecto de los prestadores del servicio educativo. Una postura resultante de políticas docentes que operan positivamente hacia su responsabilización por los resultados escolares (Fardella, 2013).

El profesorado argumenta que el Liderazgo y gestión del equipo directivo del establecimiento se dirige mayormente a la formación académica, y menos al desarrollo personal del estudiantado. Cuantitativamente, además, esbozan que el apoyo del equipo directivo a su gestión es aceptable, concentrándose esta opinión en las escuelas públicas.

En síntesis, esta revisión ha pretendido relevar la importancia del pensamiento del profesorado chileno sobre su carrera, con la proyección de contar con políticas docentes que recojan las demandas y necesidades del contexto educativo concreto y situado. Esto se justifica en Fullan (2002, citado en Fardella, 2013, p. 85), en cuando que "la implementación de las políticas, los resultados de los cambios demandados por las reformas educativas y en definitiva su éxito, encuentran su punto decisivo en los significados y prácticas de quienes están implicados en su implementación”. Asimismo, la propia ACE ha aceptado que "las políticas públicas requieren de personas involucradas y convencidas con estas medidas, por lo que conversar y reflexionar en lo que estamos de acuerdo es esencial para seguir avanzando" (2018a, p. 7).

El insumo de este trabajo demuestra la lejanía entre las pretensiones docentes y las que se definen desde la oficialidad, resultando una necesidad tan pendiente como urgente, pues las 
políticas públicas derivan acciones y estrategias de instituciones públicas y privadas, además del uso de recursos que requieren ser eficientemente aprovechados en necesidades reales, recogidas rigurosamente.

\section{Referencias}

Acuña, F., Contreras, P. y Assaél, J. (2019). Monólogo y silencio en los consejos de profesores: Posiciones subjetivas que la política educativa configura en directivos y docentes de dos escuelas públicas no selectivas de Chile. AAPE, 27(78), 1-29. DOI: https://doi.org/10.14507/epaa.27.3842/

Agencia de Calidad de la Educación. (2018a). Tarea de Todos. Hacia una visión compartida de la calidad de la educación. Recuperado de http://archivos. agenciaeducacion.cl/060308_TAREADETODOS_ONLINE.pdf

Agencia de Calidad de la Educación. (2018b). Voces de los docentes 2017. Recuperado de https://bibliotecadigital.mineduc. cl/bitstream/handle/20.500.12365/4569/Vocesdocentes. pdf?sequence $=1$ \& \&isAllowed $=y$

Arias-Ortega, K., Quintriqueo, S. y Valdebenito, V. (2018). Monoculturalidad en las prácticas pedagógicas en la formación inicial docente en La Araucanía, Chile. Educação e Pesquisa, 44, e164545. DOI: https://doi. org/10.1590/S1678-4634201711164545

Ávalos, B. (2014). La formación inicial docente en Chile: Tensiones entre políticas de apoyo y control. Estudios Pedagógicos, 40(Especial), 11-28. DOI: https://dx.doi.org/10.4067/S0718-07052014000200002

Ávalos, B. y Sotomayor, C. (2012). Cómo ven su identidad los docentes chilenos. Perspectiva Educacional, 51(1), 77-95. Recuperado de http:// perspectivaeducacional.cl/index.php/peducacional/article/view/74

Aziz, C. (2018). Gestión del cambio, creencias y teoría de acción para la mejora escolar. Nota técnica $\mathrm{N}^{\circ} 3$. Líderes Educativos. Centro de Liderazgo para la Mejora Escolar. Recuperado de https://www.lidereseducativos.cl/ wp-content/uploads/2018/07/NT3_L6_C.A._Gestion-del-cambiocreencias-y-teoria-de-la-accion_17-07-18.pdf

Barraza, P. y Leiva, I. (2018). Neuromitos en educación: Prevalencia en docentes chilenos y el rol de los medios de difusión. Paideia, (63), 17-40. Recuperado de https://revistasacademicas.udec.cl/index.php/ paideia/article/view/1166

Becerra, S. y Flores, V. (2011). Prejuicio étnico y desgaste docente: Un desafío en contextos de pobreza. Diálogos Educativos, 10(20), 14-39. 
Recuperado de http://revistas.umce.cl/index.php/dialogoseducativos/ article/view/1087

Beyer, A., Miranda, C. y Arancibia, M. (2019). Concepciones epistemológicas, pedagógicas y disciplinares de docentes de básica especializados en matemática. En B. Torres (comp.), Educación, escuela y profesorado: Aportes desde el Consejo de Decanos de Facultades de Educación del Consejo de Rectores de las Universidades Chilenas (CONFAUCE) (pp. 151-172). Editorial UDEC. Recuperado de https://editorial.udec.cl/ sites/default/files/CONFAUCE-Digital.pdf

Cabezas, V., Medina, L., Müller, M. y Figueroa, C. (2019). Desafíos y tensiones entre las nuevas políticas educativas y los programas de formación inicial de profesores en Chile. Temas de la Agenda Pública, 14(116), 1-28. Recuperado de https://repositorio.uc.cl/ xmlui/bitstream/handle/1 1534/45754/N-\%C2\%A6116\%20 Desaf\%2B\%C2\%Alos\%20y\%20tensiones\%20entre\%20las\%20 nuevas $\% 20$ pol\%2B\%C2\%Alticas $\% 20$ educativas $\% 20$ y 201 los $\% 20$ programas\%20de\%20formaci\%2B\%C2\%A6n\%20inicial\%20de\%20 profesores $\% 20$ en $\% 20$ Chile.pdf?sequence $=1$

Carrasco, C. y Ortiz, S. (2020). Trayectoria y carrera docente como política neoliberal: el caso del accountability chileno. RELEPE, 5, 1-17. DOI: https://doi.org/10.5212/retepe.v.5.15322.017

Casanova, M. (2019). Manual de Evaluación Educativa. La Muralla.

Castro, P., Agüero, C., Barraza, A., Escobar, G. y Jorquera, J. (2012). Disposición a la reflexión colectiva sistemática en docentes de un centro educativo de Chile. RMIE, 17(53), 573-591. Recuperado de http://www.scielo.org.mx/scielo.php?script=sci_arttext\&pid $=$ S1405-66662012000200012

Cavieres, E. y Apple, M. (2016). La ley docente y la clase media: Controlando el desarrollo de los profesores chilenos. Cadernos CEDES, 36(100), 265-280. DOI: https://doi.org/10.1590/cc0101-32622016171391

Centro de Estudios Mineduc. (2015). Docentes en Chile: Resultados de la encuesta TALIS 2013. Recuperado de https://centroestudios.mineduc.cl/ wp-content/uploads/sites/100/2017/06/evidencia-final_marzo_2015. pdf

Centro UC Políticas Públicas. (2016). Entrega de resultados. Voces Docentes. Una encuesta de opinión de profesores y profesoras de aula en Chile. Recuperado de https://politicaspublicas.uc.cl/wp-content//uploads/2015/11/ Encuesta-Voces-Docentes.pdf

Centro UC Políticas Públicas. (2017a). Encuesta "Voces Docentes II" (2016). Parte I: Todos pueden aprender y yo puedo enseñar a todos. 
Centro UC Políticas Públicas. (2017b). Encuesta "Voces Docentes II" (2016). Parte II: Condiciones y cultura escolar en la labor docente: Relevancia y repercusiones.

Centro UC Políticas Públicas. (2018). Voces Docentes: Tercera versión de la encuesta nacional a profesores y profesoras de aula. Una mirada a la implementación temprana de la Politica Nacional Docente.

Comisión Nacional de Acreditación (2018). Barómetro del aseguramiento de la calidad de la educación superior ( $\left.{ }^{\circ} 2\right)$. Recuperado de https:// investigacion.cnachile.cl/archivos/cna/documentos/65b_BarometroCNA-2.pdf

Contreras, J. (2018). La autonomía del profesorado. Morata.

Cornejo, R., Albornoz, N., Castañeda, L., Palacios, D., Etcheberrigaray, G., Fernández, R., Gómez, S., Hidalgo, F. y Lagos, J. I. (2015). Las prescripciones del trabajo docente en el nuevo marco regulatorio de políticas educativas en Chile. Psicoperspectivas, 14(2), 72-83. Recuperado de https://scielo.conicyt.cl/pdf/psicop/v14n2/art08.pdf

Cortez, K., Fuentes, V., Villablanca, I. y Guzmán, C. (2013). Creencias docentes de profesores ejemplares y su incidencia en las prácticas pedagógicas. Estudios Pedagógicos, XXXIX(2), 97-113. DOI: http:// dx.doi.org/10.4067/S0718-07052013000200007

Díaz, C., Solar, M., Soto, V. y Conejeros, M. (2015). Formación docente en Chile: percepciones de profesores del sistema escolar y docentes universitarios. Civilizar, 15(28), 229-246. Recuperado de http://www. scielo.org.co/pdf/ccso/v15n28/v15n28a16.pdf

Donoso, P., Rico, N. y Castro, E. (2016). Creencias y concepciones de profesores chilenos sobre las matemáticas, su enseñanza y aprendizaje. Profesorado, 20(2), 76-97. Recuperado de https://www.redalyc.org/ pdf/567/56746946005.pdf

Fardella, C. (2013). Resistencias cotidianas en torno a la institucionalización del modelo neoliberal en las políticas educacionales: El caso de la docencia en Chile. Psicoperspectivas, 12(2), 83-92. DOI: https://dx.doi. org/10.5027/psicoperspectivas-Vol12-Issue2-fulltext-294

Fardella, C. y Sisto, V. (2015). Nuevas regulaciones del trabajo docente en chile. Discurso, subjetividad y resistencia. Psicologia \& Sociedade, 27(1), 68-79. DOI: https://doi.org/10.1590/1807-03102015v27nlp068

Fernández, N. y Costillo, E. (2020). Evolución de las concepciones docentes sobre las actividades prácticas de laboratorio a partir de una formación de posgrado reflexiva. Investigações em Ensino de Ciências, 25(3), 252-269. DOI: http://dx.doi.org/10.22600/1518-8795. ienci2020v25n3p252 
Ferrada, D. (2017). Formación docente para la diversidad. Propuestas desde la región del Biobío, Chile. RMIE, 22(74), 783-811. Recuperado de http:// www.scielo.org.mx/pdf/rmie/v22n74/1405-6666-rmie-22-74-00783. pdf

Ferrada, D. y Turra, O. (2012). Las comunidades de profesores como agentes legítimos en la construcción curricular para la formación inicial. Paulo Freire, 11(11), 207-217. DOI: https://doi. org/10.25074/07195532.11.452

Ferrada, D., Villena, A. y Turra, O. (2015). Transformar la formación. Las voces del profesorado. Santiago de Chile: UCSC/RIL.

Figueroa, V. y Cavieres, E. (2020). Entre el abandono y la resistencia: Tensiones entre las concepciones profesionalizantes de la carrera y las experiencias docentes en Chile. Formação em Movimento, 2(3), 167-188. DOI: https://doi.org/10.38117/2675-181X.formov2020. v2iln3.167-188

Flores, C. (2014). Inducción de profesores novatos en Chile: un estudio de caso. Pensamiento Educativo, 51(2), 41-55. Recuperado de http:// pensamientoeducativo.uc.cl/index.php/pel/article/download/667/1310

Garay, M. y Sillard, M. (2018). Evaluación sobre los procesos formativos de los docentes de la región de Magallanes (Chile). Sophia Austral, (21), 27-42. DOI: https://dx.doi.org/10.4067/S0719-56052018000100027

García-Huidobro, J. E. (2014). Desarrollo profesional. Reflexiones de cara a la carrera docente. Docencia, 54, 64-77. Recuperado de https:// repositorio. uahurtado.cl/bitstream/handle/11242/9391/txt1124. pdf?sequence $=1$ \& isAllowed $=\mathrm{y}$

Gelber, D., González, A., Escribano, R. y Ortega, L. (2019). Del dicho al hecho: Creencias y prácticas inclusivas en establecimientos y aulas escolares en Santiago. Perspectiva Educacional, 58(3), 73-101. DOI: http://dx.doi.org/10.4151/07189729-vol.58-iss.3-art.967

Gómez-López, J. y Cano, J. (2011). El pensamiento docente y su influencia en la implantación de las Tecnologías de la Información y la Comunicación en el aula: Desafíos y oportunidades. Contextos Educativos, 14, 67-83. DOI: https://doi.org/10.18172/con.640

González. A., Gómez, M., Ahumada, G., Bravo, P., Salinas, E., Avilés, D., Pérez, J. L. y Santana, J. (2014). Principios de Desarrollo Profesional Docente construidos por y para Profesores de Ciencia: una propuesta sustentable que emerge desde la indagación de las propias prácticas. Estudios Pedagógicos, XL(número especial), 105-126. Recuperado de https://scielo.conicyt.cl/pdf/estped/v40nEspecial/art07.pdf 
Guzmán, C. (2013). Profesores ejemplares de establecimientos educativos públicos de educación secundaria y creencias pedagógicas. Desafíos y propuestas para la mejora de la docencia. RMIE, 18(58), 871-892. Recuperado de http://www.scielo.org.mx/scielo.php?script=sci_artte xt\&pid=S1405-66662013000300009

Habermas, J. (2007). Teoría de la acción comunicativa, I. Taurus.

Hederich, C., Martínez, J. y Rincón, L. (2014). Hacia una educación basada en la evidencia. Revista Colombiana de Educación, (66), 19-54. DOI: https://doi.org/10.17227/01203916.66rce19.54

Hernández, C., Pavez, A., González, A. y Tecpan, S. (2017). ¿Se sienten valorados los profesores en Chile? Educación y Educadores, 20(3), 434447. DOI: https://dx.doi.org/10.5294/edu.2017.20.3.6

Ley $N^{\circ}$ 19.961. Sobre Evaluación Docente. 14 de agosto de 2004. Diario Oficial de la República de Chile, $\mathrm{N}^{\circ}$ 37.936. Recuperado de https:// www.diariooficial.interior.gob.cl/media/2004/08/14/do-20040814.pdf

Ley $\mathrm{N}^{\circ}$ 20.529. Sistema Nacional de Aseguramiento de la Calidad de la Educación Parvularia, Básica y Media y su Fiscalización. 27 de agosto de 2011. Diario Oficial de la República de Chile, No 40.046. Recuperado de https://www.diariooficial.interior.gob.cl/media/2011/08/27/do20110827.pdf

Ley No 20.903. Crea el Sistema de Desarrollo Profesional Docente y modifica otras normas. 01 de abril de 2016. Diario Oficial de la República de Chile, $\mathrm{N}^{\circ}$ 41.421. Recuperado de https://www.diariooficial.interior. gob.cl/media/2016/04/01/do-20160401.pdf

Medina, J. L. (2006). La profesión docente y la construcción del conocimiento profesional. Magisterio del Río de la Plata.

Ministerio de Educación. República de Chile. (2008). Marco para la Buena Enseñanza. Recuperado de https://www.docentemas.cl/docs/MBE2008. pdf

Ministerio de Educación. República de Chile. (2012). Estándares Orientadores para Egresados de Carreras de Pedagogía en Educación Básica (Segunda edición). Recuperado de https://www.cpeip.cl/wp-content/ uploads/2016/07/librobasicaokdos.pdf

Miño, A. (2016). Calidad de vida laboral en docentes chilenos. Summa Psicológica UST, 13(2), 45-55. DOI: https://doi.org/10.18774/summavol13.num2-256/

Morales, M., Álvarez, J.P., Ayala, A., Ascorra, P., Bilbao, M., Carrasco, C., López, V., Olavarría, D., Ortiz, S., Urbina, C. y Villalobos, B. (2014). 
Violencia escolar a profesores: Conductas de victimización reportadas por docentes de enseñanza básica. Revista de Estudios Cotidianos, 2(2), 91-116. Recuperado de https://dialnet.unirioja.es/descarga/ articulo/5118372.pdf

Muñoz, M., López, M. y Assaél, J. (2015). Concepciones docentes para responder a la diversidad: ¿Barreras o recursos para la inclusión educativa? Psicoperspectivas, 14(3), 68-79. DOI: http://dx.doi. org/10.5027/psicoperspectivas-Voll4-Issue3-fulltext-646

Organización para la Cooperación y el Desarrollo Económico. (2014). TALIS 2013 Results: An International Perspective on Teaching and Learning. DOI: https://dx.doi.org/10.1787/9789264196261-en/

Organización para la Cooperación y el Desarrollo Económico. (2019). TALIS 2018 Results (Volume I): Teachers and School Leaders as Lifelong Learners. Nota País Chile. DOI: https://doi.org/10.1787/1d0bc92a-en/

Pascual, J. y Navío-Gámez, A. (2018). Concepciones sobre innovación educativa. ¿Qué significa para los docentes en Chile? Profesorado, 22(4), 71-90. DOI: https://doi.org/10.30827/profesorado.v22i4.8395

Pontes, A., Poyato, F. y Oliva, J. M. (2018). Estudio de las creencias sobre la enseñanza de las ciencias que presentan los estudiantes del máster de profesorado de enseñanza secundaria. Revista Electrónica de Enseñanza de las Ciencias, 17(3), 581-601. DOI: https://doi.org/10.7203/ dces. 31.7881

Puga, I., Polanco, D. y Corvalán, D. (2015). Segregación de la formación y carrera docente y su rol en la reproducción social de la desigualdad. Calidad de la Educación, 43, 57-102. DOI: http://dx.doi.org/10.4067/ S0718-45652015000200003

Prats, E. (2016). La Formación Inicial Docente entre profesionalismo y vías alternativas: mirada internacional. Bordón, 68(2), 19-33. Recuperado de https://recyt.fecyt.es/index.php/BORDON/article/view/38464/30229

Ramírez, R., Meneses, J. y Floréz, M. (2013). Una propuesta metodológica para la conducción de revisiones sistemáticas de la literatura en la investigación biomédica. CES Movimiento y Salud, 1(1), 61-73.

Roa, K. A. (2017). La evaluación docente bajo la óptica del desarrollo profesional: el caso chileno. Educación y Educadores, 20(1), 41-61. DOI: http://dx.doi.org/10.5294/edu.2017.20.1.3

Rojas, M. (2014). Las creencias docentes: Delimitación del concepto y propuesta para la investigación. Diálogos Educativos, 14(27), 89-112. Recuperado de https://dialnet.unirioja.es/servlet/ articulo? codigo $=4829634$ 
Ruffinelli, A. (2013). La calidad de la formación inicial docente en Chile: la perspectiva desde los docentes principiantes. Calidad en la Educación, (39), 117-154. DOI: https://dx.doi.org/10.4067/S071845652013000200005

Ruffinelli, A. (2014a). Dificultades de la iniciación docente: ¿iguales para todos? Estudios Pedagógicos, 40(1), 229-242. https://dx.doi. org/10.4067/S0718-07052014000100014

Ruffinelli, A. (2014b). ¿Qué aprenden los docentes en su primer año de ejercicio profesional?: Representaciones de los propios docentes principiantes. Pensamiento Educativo, 51(2), 56-74. Recuperado de http://pensamientoeducativo.uc.cl/index.php/pel/article/ download/658/1311

Ruffinelli, A. (2016). Ley de desarrollo profesional docente en Chile: de la precarización sistemática a los logros, avances y desafíos pendientes para la profesionalización. Estudios Pedagógicos, XLII(4), 261-279. DOI: http://dx.doi.org/10.4067/S0718-07052016000500015

Salinas, J., Oller, M. y Muñoz, C. (2016). Representaciones sociales de la participación ciudadana en docentes de ciencias sociales: perspectivas para la nueva asignatura de formación ciudadana en Chile. Foro Educacional, (27), 141-161. DOI: https://doi. org/10.29344/07180772.27.801

San Martín, C. (2012). Atención de la diversidad en el contexto educativo chileno: Concepciones del profesorado sobre evaluación y diseño de la propuesta curricular. REICE, 10(4), 165-183. Recuperado de http:// www.rinace.net/reice/numeros/arts/vollonum4/art11.pdf

Santelices, M. V., Galleguillos, P., González, J. y Taut, S. (2015). Un estudio sobre la calidad docente en Chile: El rol del contexto en donde enseña el profesor y medidas de valor agregado. PSYKHE, 24(1), 1-14. Recuperado de https://www.scielo.cl/scielo.php?script=sci_ abstract\&pid=S0718-22282015000100004\&lng=es\&nrm=iso\&th $\mathrm{g}=\mathrm{es}$

Sepúlveda, A., Hernández-Mosqueira, C., Peña-Troncoso, S., Troyano, M. A. y Opazo, M. (2019). Evaluación del desempeño docente en Chile: Percepción de profesores mal evaluados. Cadernos de Pesquisa, 49(172), 144-163. DOI: https://doi.org/10.1590/198053145792

Sisto, V. (2012). Identidades Desafiadas: Individualización, Managerialismo y Trabajo Docente en el Chile Actual. PSYKHE, 21(2), 35-46. Recuperado de https://scielo.conicyt.cl/pdf/psykhe/v21n2/art04.pdf

Schilling, C. y Sánchez, G. (2020). Cambios en las políticas de formación docente en Chile: análisis del curriculum de formación práctica de 
una universidad regional del Maule. Formacao Docente, 12(23), 67-82. DOI: https://doi.org/10.31639/rbpfp.v12i23.288

Tapia, C. y Cubo, S. (2017). Habilidades sociales relevantes: percepciones de múltiples actores educativos. MAGIS, 9(19), 133-148. DOI: https:// doi.org/10.11144/Javeriana.m9-19.hsrp

Tenorio, S., Jardi, A., Puigdellívol, I. e Ibáñez, N. (2020). Intersección escuelauniversidad: un espacio híbrido de colaboración para fortalecer la formación inicial y el desarrollo profesional docente. Perspectiva Educacional, 59(2), 88-110. DOI: http://dx.doi.org/10.4151/07189729vol.59-iss.2-art.1071

Venegas, C. (2013). Hacia la innovación en la formación inicial docente para un desempeño exitoso en contextos alta vulnerabilidad social y educativa. REXE, 12(23), 47-59. Recuperado de http://www.rexe.cl/ ojournal/index.php/rexe/article/view/78/73

Vergara, C. (2011). Concepciones de evaluación del aprendizaje de docentes chilenos. Acción Pedagógica, (20), 6-18. Recuperado de http://www. saber.ula.ve/handle/123456789/34322

Wilhelm, K., Martin, G. y Miranda, Ch. (2012). Autoestima profesional: competencia mediadora en el marco de la evaluación docente. Revista Latinoamericana de Ciencias Sociales, Niñez y Juventud, 10(1), 339-350. Recuperado de https://www.redalyc.org/pdf/773/77323982020.pdf

Recibido: 21/04/2021

Aceptado: 24/11/2021 